\title{
Analisis Preferensi Konsumen Buah Pisang sebagai Komoditi Unggulan di Kota Langsa
}

\author{
Fiddini Alham ${ }^{1}$ \\ Faoeza Hafiz Saragih ${ }^{2 *}$ \\ 1,2 Program Studi Agribisnis Fakultas Pertanian Universitas Samudra \\ *e-mail: hafizsaragih@unsam.ac.id \\ Diterima: September 2020; Disetujui: Februari 2021; Dipublish: April 2021
}

\begin{abstract}
Abstrak
Pisang di Kota Langsa merupakan salah satu komoditi buah unggulan dimana pisang adalah buah dengan produksi terbesar. informasi preferensi konsumen terhadap buah-buahan unggulan di Kota Langsa akan membuat produsen memproduksi buah-buahan dengan kualitas yang sesuai dengan keinginan konsumen, sehingga produksi dapat terserap kepasar dan dapat meningkatkan pendapatan dan perekonomian daerah. Penelitian ini dilakukan di Pusat Pasar Kota Langsa dengan jumlah sampel sebanyak 60 responden yang diambil melalui metode accendental sampling. Metode analisis yang dilakukan adalah dengan metode analisis factor untuk melihat preferensi konsumen buah pisang. Hasil penelitian menunjukkan bahwa terdapat lima aspek yang terbentuk, dimana aspek buah menjadi aspek dengan nilai keragaman terbesar dan variabel ketersediaan buah pisang lokal dipasar menjadi variabel pertimbangan konsumen terbesar dikarenakan tedapat pasar khusus yang menjual buah pisang di Kota Langsa.
\end{abstract}

Kata Kunci: Pisang, Preferensi, Konsumen, Unggulan

\begin{abstract}
Banana in Langsa City is one of the leading fruit commodities where banana is the fruit with the largest production. Information on consumer preferences for prime fruits in Langsa City will make producers produce fruits with quality according to consumer desires so that production can be absorbed into the market and can increase regional income and economy. This research was conducted at Langsa City Market Center with a total sample of 60 respondents who were taken through the accidental sampling method. The method of analysis used is the factor analysis method to see consumer preferences for bananas. The results showed that five aspects were formed, where the aspect of fruit was the aspect with the greatest diversity value and the variable availability of local bananas in the market was the biggest consumer consideration variable because there was a special market that sold bananas in Langsa City.
\end{abstract}

Keywords: Banana; Preference; Consumer; Prime

\section{PENDAHULUAN}

Buah lokal lebih diminati dari pada buah impor (Sumarwan \& Palupi, 2017). Namun penelitian ini sedikit bertolak belakang dengan maraknya buah impor di supermarket hingga pasar tradisional. Menurut data impor buah-buahan negara asal utama dari tahun 2016-2019 yang dirilis BPS (2020), negara Tiongkok adalah negara terbesar pengimpor dengan pertumbuhan yang selalu positif setiap tahunnya, disusul oleh Amerika Serikat dan seterusnya. Salah satu buah impor yang marak di pasar-pasar Indonesia adalah apel, dimana dalam penelitian Rahayu, Fauziyah, \& Ariyani (2012) buah impor diminati karena harga yang murah, faktor warna buah, ukuran, tekstur, dan faktor kemasan. Maka berdasarkan data dan penelitian diatas maka dapat disimpulkan bahwa 
buah lokal lebih diminati, namun kalah bersaing dari buah impor untuk jenis buah tertentu, terutama dari segi harga dan dari distrubusi.

Capaian konsumsi sayur dan buah masih menjadi masalah yang disoroti di Indonesia, Badan Kesehatan Dunia secara umum menganjurkan konsumsi sayuran dan buah-buahan untuk hidup sehat sejumlah 400 gram per orang per hari (Rizkyana, Nugroho, \& Anggraeny, 2017). Secara garis besar konsumsi buah dan sayur di Indonesia menurun dan tidak memadai, hanya sekitar $43 \%$ masyarakat yang mengkonsumsi sesuai dengan yang direkomendasikan pada tahun 2016. Beberapa penelitian lainnya menunjukkan bahwa konsumsi buah dan sayur yang masih kurang baik pada masa remaja di Indonesia dipengaruhi oleh sikap, pengetahuan gizi, ketersediaan makanan, keterpaparan media, pendapatan keluarga (Rachman, Mustika, \& Kusumawati, 2017), hal yang sama juga dikemukakan pada penelitian (Bahria, 2010).

Produksi untuk beberapa jenis buahbuahan tertentu, seperti pisang, nenas, pepaya, mengalami pertumbuhan produksi dibawah $2 \%$, bahkan salak mengalami pertumbuhan yang negatif di tahun 2017-2018. Hal ini yang menyebabkan Indonesia menjadi sasaran pasar buah impor. Ditambah lagi kesadaran konsumen untuk mengkonsumsi buah lokal masih berada pada posisi rendah, terutama dibandingkan dengan buah-buahan impor (Rochaeni, 2013). Kota Langsa sebagai salah satu kota di Provinsi Aceh memiliki potensi buah-buahan yang potensial. Adapun data produksi buahbuahan di Kota Langsa dapat dilihat pada Tabel 2. dari tabel tersebut dapat dilihat bahwa buah pisang merupakan produksi buah terbanyak di Kota Langsa, hal ini sinkron dengan data pada tabel 1 . dimana buah pisang merupakan buah dengan produksi terbesar di Indonesia. Dengan tingkat produksi yang tinggi menjadikan buah pisang merupakan salah satu buah lokal unggulan di Kota Langsa. Dalam mengkonsumsi sebuah produk termasuk buah lokal, konsumen tentunya memperhatikan wujud fisik, penyajian juga menjadi perhatian dalam memenuhi kepuasan konsumen. Dengan penjelasan diatas, maka sangat penting bagi produsen buah lokal memperhatikan kebutuhan konsumen yang dianggap penting pada atribut buah lokal. Tentunya produsen dapat meningkatkan kualitas buah lokal. Menurut Sungkawa, Dwi, \& Eva (2015) preferensi konsumen dalam memilih produk yang sesuai dengan keinginan, kepentingan selera untuk buah lokal dipengaruhi oleh beberapa variabel, seperti ketersediaan, harga, kualitas (rasa, warna, bentuk ukuran, kandungan gizi, kesegaran dan aroma). Penelitian lain menambahkan persepsi konsumen terhadap buah lokal seperti motivasi, kebersihan, pandangan dan lokasi (Simbolon, Zargustin, \& Nizar, 2018). 
Tabel 1. Produksi 10 Buah Teratas Untuk Komoditi Yang Paling Banyak Diproduksi 2017-2018 Indonesia

\begin{tabular}{clrrrr}
\hline \multirow{2}{*}{ No } & Jenis Tanaman & \multicolumn{2}{c}{ Produksi (ton) } & \multicolumn{2}{c}{ Pertumbuhan } \\
\cline { 3 - 6 } & & $\mathbf{2 0 1 7}$ & $\mathbf{2 0 1 8}$ & $\begin{array}{c}\text { Absolut } \\
\text { (Ton) }\end{array}$ & \multicolumn{1}{c}{$\%$} \\
\hline 1 & Pisang & 7.162 .686 & 7.264 .383 & 101.698 & 1,42 \\
2 & Mangga & 2.203 .793 & 2.624 .791 & 420.998 & 19,10 \\
3 & Jeruk Siam & 2.165 .192 & 2.408 .043 & 242.851 & 11,22 \\
4 & Nenas & 1.795 .986 & 1.805 .506 & 9.520 & 0,53 \\
5 & Durian & 795.211 & 1.142 .102 & 346.891 & 43,62 \\
6 & Salak & 953.853 & 896.504 & $(57.349)$ & $(6,01)$ \\
7 & Pepaya & 875.112 & 887.591 & 12.479 & 1,43 \\
8 & Nangka & 656.583 & 775.480 & 118.897 & 18,11 \\
9 & Rambutan & 523.704 & 715.935 & 192.231 & 36,71 \\
10 & Apel & 319.004 & 481.651 & 162.647 & 50,99 \\
\hline
\end{tabular}

Sumber: (BPS, 2018)

Dengan diketahuinya preferensi konsumen maka produsen dapat meningkatkan kuantitas produksi pisang sehingga nantinya diharapkan dapat dijual keluar Kota Langsa dan pada akhirnya akan meningkatkan pendapatan petani. Disamping itu pula terdapat pasar khusus yang menjual pisang yang dikenal dengan nama Pajak Pisang. Di pasar ini banyak berbagai jenis pisang yang dijual, terutama jenis pisang barangan baik yang berasal dari Kota Langsa maupun dari luar Kota Langsa. Berdasarkan pemaparan sebelumnya perlu diketahui preferensi konsumen buah pisang di Kota Langsa sebagai salah satu buah unggulan. Sehingga produsen dan pemerintah daerah dapat memenuhi permintaan sesuai dengan kebutuhan konsumen.

\section{METODE PENELITIAN}

Penelitian ini dilaksanakan di pasar tradisional Kota Langsa yang merupakan satu-satunya pasar dimana penjualan akhir buah terdapat dipasar ini. Pada pasar ini terdapat pasar khusus yang menjual berbagai jenis pisang baik yang lokal maupun dari luar Kota Langsa. Populasi dalam penelitian ini adalah konsumen dari buah pisang dimana metode pengambilan sampel dilakukan secara accendental sampling sebanyak 60 responden. Pengumpulan data dalam penelitian ini dilakukan dengan metode pengumpulan data primer dan sekunder.

Tabel 2. Data Produksi Buah di Kota Langsa 2018-2019

\begin{tabular}{lrrr}
\hline \multirow{2}{*}{ Jenis Tanaman } & \multicolumn{3}{c}{ Tahun (Kw) } \\
\cline { 2 - 4 } & $\mathbf{2 0 1 8}$ & $\mathbf{2 0 1 9}$ \\
\hline Pisang & & 1.977 & 1.823 \\
Rambutan & 1.535 & 1.046 \\
Mangga & 1.752 & 1.061 \\
Durian & 1.295 & 694 \\
Nangka & 773 & 523 \\
\hline
\end{tabular}

Sumber: (BPS Langsa, 2020) 
Data primer diperoleh melalui wawancara dan diskusi secara langsung kepada sampel. Data sekunder diperoleh dari instansi terkait yaitu BPS dan jurnal.

Metode analisis data yang digunakan dalam penelitian ini adalah analisis faktor dimana metode ini untuk mengetahui prioritas konsumen dalam membeli buah pisang lokal. Terdapat tujuh belas item pernyataan dalam kuesioner penelitian ini, yang mana pernyataan tersebut antara lain sebagai berikut: ukuran, bentuk, warna buah, rasa, kesegaran, aroma, pengemasan/ penataan, buah baru, buah lokal, buah luar kota, ketersediaan, kemudahan, promosi, harga sesuai, buah lokal lebih murah, buah luar kota lebih murah dan potongan harga.

\section{HASIL DAN PEMBAHASAN}

Sebelum dilakukan analisis factor terdapat beberapa tahapan yang harus dilakukan untuk memastikan item-item pertanyaan yang diajukan sudah layak atau tidak. Kaiser-Meyer-Olkin and Bartlett's tests adalah pengujian yang digunakan untuk mengetahui apakah pertanyaan-pertanyaan yang menjadi obyek analisis sudah layak untuk dimasukkan dalam analisis faktor. Koefisien KMO digunakan untuk mengukur serta mengetahui kecukupan sampel yang digunakan dapat dilihat dengan menggunakan koefisien KMO dimana, KMO Measure of Sampling Adequency harus diatas 0,50 sehingga dapat dinyatakan cukup kuat (Mahmudah, 2019). Hasil uji KMO dalam penelitian ini adalah sebesar 0,679 dengan signifikansi 0,000 , sehingga dapat disimpulkan bahwa analisis faktor layak untuk dilakukan. Kemudian tahap berikutnya adalah factoring yaitu melakukan ekstraksi/reduksi variabel asli menjadi beberapa faktor yang dapat mewakili seluruh variabel asli dengan menggunakan metode Principal Component Analisis (PCA). Variabel dapat dinyatakan mampu untuk menjelaskan faktor atau tidak dilihat dari nilai extraction $>0,50$. Pada penelitian ini seluruh variabel memiliki nilai extraction $>$ 0,50 yang berarti bahwa variabelvariabel yang diuji mampu menjelaskan analisis faktor.

Tabel 3. Hasil Uji KMO and Bartlett's Test

KMO and Bartlett's Test

\begin{tabular}{llr}
\hline Kaiser-Meyer-Olkin Measure of Sampling Adequacy. & .679 \\
Bartlett's Test of & Approx. Chi-Square & 291.378 \\
Sphericity & Df & 136 \\
& Sig. & .000 \\
\hline
\end{tabular}

Sumber : Data Primer, diolah (2020)

Berikutnya adalah penentuan dapat dilihat pada nilai total jumlah faktor yang terbentuk yang eigenvalue. 
Tabel 4. Uji Communalities

\begin{tabular}{lrc}
\hline & Initial & Extraction \\
\hline Ukuran Buah & 1.000 & .784 \\
Bentuk Buah & 1.000 & .767 \\
Warna Buah & 1.000 & .505 \\
Rasa Buah & 1.000 & .831 \\
Kesegaran Buah & 1.000 & .569 \\
Aroma Buah & 1.000 & .682 \\
Pengemasan/penataan Buah & 1.000 & .523 \\
Buah Baru & 1.000 & .608 \\
Buah Lokal & 1.000 & .698 \\
Buah Nonlokal & 1.000 & .767 \\
Selalu Tersedia di Pasar & 1.000 & .694 \\
Mudah Untuk Mendapatkan & 1.000 & .658 \\
Ada Promosi & 1.000 & .767 \\
Harga Sesuai Dengan Kualitas & 1.000 & .503 \\
Harga Buah Lokal Lebih Murah & 1.000 & .611 \\
Harga Buah Nonloka Lebih Murah & 1.000 & .591 \\
Ada Potongan harga & 1.000 & .619 \\
\hline
\end{tabular}

Sumber : Data Primer, diolah (2020)

Penentuan jumlah faktor yang terbentuk yang dapat dilihat pada nilai total eigenvalue $>1$. Berdasarkan tabel 5 maka terdapat 5 buah faktor yang terbentuk dan mampu menjelaskan sebesar $65.752 \%$ variasi. Langkah selanjutnya adalah mengelompokkan

Tabel 5. Total Variance Explained

\begin{tabular}{|c|c|c|c|c|c|c|}
\hline \multirow{2}{*}{ Component } & \multicolumn{3}{|c|}{ Initial Eigenvalues } & \multicolumn{3}{|c|}{$\begin{array}{c}\text { Rotation Sums of Squared } \\
\text { Loadings }\end{array}$} \\
\hline & Total & $\begin{array}{c}\text { \% of } \\
\text { Variance }\end{array}$ & $\begin{array}{c}\text { Cumulative } \\
\%\end{array}$ & Total & $\begin{array}{c}\text { \% of } \\
\text { Variance }\end{array}$ & $\begin{array}{c}\text { Cumulative } \\
\%\end{array}$ \\
\hline 1 & 5.035 & 29.617 & 29.617 & 5.035 & 29.617 & 29.617 \\
\hline 2 & 2.460 & 14.472 & 44.088 & 2.460 & 14.472 & 44.088 \\
\hline 3 & 1.449 & 8.524 & 52.612 & 1.449 & 8.524 & 52.612 \\
\hline 4 & 1.214 & 7.143 & 59.755 & 1.214 & 7.143 & 59.755 \\
\hline 5 & 1.020 & 5.997 & 65.752 & 1.020 & 5.997 & 65.752 \\
\hline 6 & .916 & 5.388 & 71.140 & & & \\
\hline 7 & .864 & 5.084 & 76.224 & & & \\
\hline 8 & .739 & 4.347 & 80.571 & & & \\
\hline 9 & .657 & 3.864 & 84.435 & & & \\
\hline 10 & .547 & 3.216 & 87.650 & & & \\
\hline
\end{tabular}

variabel sesuai dengan korelasinya terhadap masing- masing faktor. Pada tabel 5 menampilkan nilai loading factor yang menunjukkan besarnya korelasi tiap variabel dalam kelima faktor yang terbentuk. 


$\begin{array}{rrrr}11 & .526 & 3.092 & 90.743 \\ 12 & .435 & 2.559 & 93.301 \\ 13 & .398 & 2.340 & 95.642 \\ 14 & .259 & 1.521 & 97.163 \\ 15 & .198 & 1.165 & 98.327 \\ 16 & .170 & 1.002 & 99.330 \\ 17 & .114 & .670 & 100.000\end{array}$

Sumber : Data Primer, diolah (2020)

Berdasarkan tabel 6. maka dapat dikelompokkan variabel-variabel yang membentuk kelima 5 faktor tersebut. Berikutnya adalah memberikan penamaan terhadap factor - faktor yang terbentuk dalam hasil analisis factor yaitu dengan memberikan penamaan yang mempresentasikan nama nama variabel yang terbentuk atau penamaan berdasarkan variabel yang memiliki nilai factor loaded tertinggi (Pradana, Slamet, \& Andrianto, 2018). Dalam penelitian ini penamaan dilakukan berdasarkan presentasi dari nama-nama variabel yang terbentuk.

Pemberian nama faktor pada tabel berdasarkan nilai faktor

Tabel 6. Component Matrix

\begin{tabular}{lccccc}
\hline & \multicolumn{5}{c}{ Component } \\
\cline { 2 - 6 } & $\mathbf{1}$ & $\mathbf{2}$ & $\mathbf{3}$ & $\mathbf{4}$ & $\mathbf{5}$ \\
\hline Ukuran Buah & -.373 &. $\mathbf{6 7 6}$ & -.080 & .077 & .419 \\
Bentuk Buah & -.676 & .364 & -.409 & -.101 & -.033 \\
Warna Buah & .384 &. $\mathbf{3 9 3}$ & -.287 & -.336 & -.092 \\
Rasa Buah & $\mathbf{. 6 1 8}$ & .369 & -.238 & -.506 & .030 \\
Kesegaran Buah & $\mathbf{. 6 6 1}$ & .364 & -.075 & -.319 & -.121 \\
Aroma Buah & $\mathbf{. 7 7 5}$ & .173 & -.021 & .165 & .154 \\
Pengemasan/penataan Buah & .394 & -.064 & -.468 & .245 & .289 \\
Buah Baru & $\mathbf{. 7 3 7}$ & .130 & .158 & .152 & .010 \\
Buah Lokal & -.712 & .310 & -.113 & .232 & .170 \\
Buah Nonlokal & -.538 & .300 &. $\mathbf{5 7 1}$ & -.022 & -.247 \\
Selalu Tersedia di Pasar &. $\mathbf{8 0 0}$ & .028 & .210 & .077 & .058 \\
Mudah Untuk Mendapatkan &. $\mathbf{6 9 4}$ & .132 & .334 & .184 & -.120 \\
Ada Promosi & .117 & .286 & .507 & -.055 &. $\mathbf{6 4 2}$ \\
Harga Sesuai Dengan Kualitas & .219 &. $\mathbf{5 8 6}$ & .116 & -.002 & -.314 \\
Harga Buah Lokal Lebih Murah & -.271 &. $\mathbf{6 0 4}$ & .089 & .311 & -.262 \\
Harga Buah Nonlokal Lebih Murah & -.461 & .268 & .244 & -.481 & .127 \\
Ada Potongan harga & .180 &. $\mathbf{5 7 7}$ & -.233 & .438 & -.088 \\
\hline
\end{tabular}

Sumber : Data Primer, diolah (2020)

variabel asli yang terbesar dari masingmasing faktor, didapatkan 5 faktor yang mempengaruhi konsumen dalam membeli buah pisang di Kota Langsa. 
Urutan faktor yang paling dominan mempengaruhi konsumen dalam membeli buah pisang dapat dilihat melalui nilai keragaman yang dapat dijelaskan oleh masing- masing faktor. Tabel berikut menunjukkan urutan faktor- faktor yang mempengaruhi konsumen dalam membeli buah pisang.

\section{Faktor Aspek Buah}

Faktor pertama yang terbentuk dan paling dominan adalah faktor aspek buah. Aspek buah adalah menjadi faktor yang paling dominan mempengaruhi konsumen dalam membeli buah pisang dengan nilai keragaman sebesar $29.617 \%$. dari beberapa variabel responden memberikan nilai tinggi pada salah satu variabel yang ditunjukkan dengan nilai loading faktor sebesar 0,800 yaitu variabel yang menyatakan buah pisang selalu tersedia di pasar. Hal ini mengingat bahwa di Kota Langsa terdapat pasar khusus yang menjual berbagai jenis pisang dan selalu tersedia sepanjang hari. Pisang-pisang yang dijual dipasar ini merupakan pisang yang berasal dari buah lokal karena banyak penduduk yang menanam pisang terutama berasal dari Kecamatan Langsa Timur. Adapun variabel dengan nilai loading faktor terendah dalam faktor aspek ini adalah kesegaran buah yang dibeli dengan nilai sebesar 0,561 . Pada pasar pisang tersebut buah pada umumnya dalam keadaan segar bahkan ada yang masih berwarna hijau, adapun buah yang telah tidak segar/busuk tidak dijual.

Tabel 7. Faktor- Faktor yang Mempengaruhi Keputusan Konsumen dalam Membeli Buah Pisang

\begin{tabular}{|c|c|c|}
\hline Faktor & $\begin{array}{l}\text { Loading } \\
\text { Faktor }\end{array}$ & $\begin{array}{l}\text { Variance } \\
(\%)\end{array}$ \\
\hline \multicolumn{3}{|l|}{ Aspek Buah } \\
\hline $\begin{array}{l}\text { Bentuk buah yang simetris/ seragam/ menarik/ } \\
\text { proporsional }\end{array}$ & -.676 & \multirow{8}{*}{29.617} \\
\hline Rasa yang manis dan kesegaran buah & .618 & \\
\hline Kesegaran buah yang dibeli & .561 & \\
\hline Aroma buah yang matang dan wangi & .775 & \\
\hline Buah dalam kondisi segar, tidak boyok, busuk & .737 & \\
\hline Buah berasal dari Kota Langsa & -.712 & \\
\hline Buah selalu tersedia di pasar & .800 & \\
\hline Buah lokal mudah untuk didapatkan di pasar & .694 & \\
\hline \multicolumn{3}{|l|}{$\begin{array}{c}\text { Aspek Fisik dan Harga } \\
\end{array}$} \\
\hline Ukuran buah yang besar dan berat & .676 & \multirow{5}{*}{14.472} \\
\hline $\begin{array}{l}\text { Warna buah yang cerah dan bersih sesuai dengan tingkat } \\
\text { kematangan buah }\end{array}$ & .393 & \\
\hline Harga buah yang ditawarkan sesuai dengan kualitas & .586 & \\
\hline $\begin{array}{l}\text { Harga buah lokal yang ditawarkan murah dibanding buah } \\
\text { luar }\end{array}$ & .604 & \\
\hline $\begin{array}{l}\text { Mendapatkan potongan harga apabila membeli buah dalam } \\
\text { jumlah tertentu }\end{array}$ & .577 & \\
\hline \multicolumn{3}{|l|}{ Aspek Pengemasan dan Asal Buah } \\
\hline $\begin{array}{l}\text { Buah di taruh di tempat atau wadah yang baik dan bersih } \\
\text { Buah berasal dari luar Kota Langsa }\end{array}$ & $\begin{array}{ll}-.468 \\
.571\end{array}$ & 8.524 \\
\hline
\end{tabular}




\begin{tabular}{lcc}
\hline $\begin{array}{l}\text { Harga buah luar yang ditawarkan lebih murah dari buah } \\
\text { lokal }\end{array}$ & -.481 & 7.143 \\
\hline \multicolumn{1}{c}{ Aspek Promosi } \\
\hline $\begin{array}{l}\text { Promosi buah unggulan telah dilakukan oleh pemerintah } \\
\text { kota }\end{array}$ & .642 & 5.997 \\
\hline Sumber: Data Primer, diolah (2020) &
\end{tabular}

\section{Aspek Fisik dan Harga}

Aspek fisik dan harga menjadi faktor kedua terbesar yang terbentuk dengan nilai keragaman sebesar $14.472 \%$. Aspek fisik dan harga yang diperhatikan konsumen dalam membeli adalah ukuran buah yang besar dan berat dimana sebagian responden membeli pisang untuk dijadikan konsumsi langsung atau untuk dibuat menjadi keripik sehingga menginginkan buah yang besar dengan nilai loading factor nya adalah sebesar 0.676. variabel dengan nilai loading factor terendah adalah warna buah yang cerah dan bersih sesuai dengan tingkat kematangan yaitu sebesar 0,393. Konsumen tidak terlalu mempertimbangkan warna buah yang cerah karena pada pisang terdapat bintik-bintik hitam yang menjadi ciri dari pisang barangan, hal ini sesuai dengan penelitian yang dilakukan oleh Permadi \& Winarti (2015) yang menyatakan bahwa atribut kebersihan kulit pisang bagi konsumen di Kota Sampit biasa saja (netral).

\section{Aspek Pengemasan dan Asal Buah}

Aspek ketiga adalah pengemasan dan asal buah dengan indikator nilai keragaman sebesar 8,524\% dimana variabel terbesar yang mempengaruhi adalah buah berasal dari luar Kota Langsa. Beberapa responden membeli buah pisang yang berasal dari luar kota dikarenakan buah pisang yang diinginkan sesuai dengan selera konsumen yaitu jenis pisang yang lebih besar dari pisang lokal dengan nilai loading factor nya sebesar 0,571. Adapun pisang ini terutama berasal dari Provinsi Sumatera Utara. Variabel lain pada aspek ini adalah pengemasan buah yang baik dan bersih, pada umumnya buah pisang yang dijual pada pasar ini digantung dan tersusun dengan rapi sehingga pembeli bisa dengan leluasa memilih pisang yang diinginkan. Sedangkan buah pisang yang belum matang atau telah busuk ditaruh dibawah dan belum dipajang. Hal ini berbeda dengan buah pisang yang telah diolah semisal pisang sale yang menjadi salah satu ciri khas dari Provinsi Aceh. Dimana kemasan pisang sale yang bersih dan higienis menjadi faktor utama bagi konsumen untuk membeli dan kemasan yang rusak menjadi faktor penghambat konsumen untuk membeli (Hasanawi \& Kesumawati, 2015).

\section{Aspek Harga Buah Non Lokal}

Aspek berikutnya adalah harga buah non lokal yang lebih murah dibandingkan dengan buah lokal dengan nilai keragaman sebesar 7,143\%. Aspek harga buah yang murah menjadi indikator harga yang penting bagi konsumen dalam membeli pisang. Adapun nilai loading factor nya adalah sebesar -0,471, hal ini menunjukkan bahwa semakin tinggi harga buah pisang non lokal maka konsumen tidak akan memilihnya untuk dibeli. Harga buah 
pisang yang ditawarkan oleh penjual berkisar antara Rp. 10.000- Rp. 15.000, bergantung kepada ukuran dan asal buah pisangnya.

\section{Aspek Promosi}

Aspek terakhir adalah promosi yang dilakukan oleh pedagang dengan nilai keragaman sebesar 5,997\%. Konsumen tidak terlalu mementingkan sekali promosi yang dilakukan dimana nilai loading factor nya sebesar 0,642. Pasar buah pisang yang terdapat di Kota Langsa merupakan salah satu bentuk pasar persaingan sempurna dimana banyak terdapat penjual dengan menjual jenis pisang yang memiliki keragaman yang sama sehingga konsumen memiliki kebebasan dalam membeli pisang.

\section{SIMPULAN}

Preferensi konsumen dalam membeli buah pisang di Kota Langsa terebsar adalah aspek buah dimana dalam aspek ini variabel ketersediaan buah menjadi alasan utama konsumen membeli pisang, hal ini disebabkan pasar khusus yang menjual pisang tersedia di kota ini sehingga memudahkan konsumen mendapatkan buah dan juga tentunya memudahkan petani untuk menjual pisangnya. Pemerintah daerah sebaiknya menjaga serta mempromosikan keberadaan pasar pisang ini serta pedagang mulai untuk menjual dalam bentuk olahan pula sehingga dapat menjadi sentra oleh-oleh khas Kota Langsa.

\section{UCAPAN TERIMA KASIH}

Kami ingin mengucapkan terima kasih kepada DRPM Kementerian Riset, Teknologi, dan Pendidikan Tinggi (KEMENRISTEKDIKTI) sebagai lembaga yang telah mendanai penelitian ini melalui skema Penelitian Dosen Pemula 2020. Selain itu kepada Lembaga Penelitian dan Pengabdian Masyarakat Universitas Samudra, yang telah berkontribusi secara moral dan material dalam pelaksanaan penelitian ini.

\section{DAFTAR PUSTAKA}

Bahria. (2010). Faktor-Faktor Yang Terkait Dengan Konsumsi Buah Dan Sayur Pada Remaja Di 4 SMA Di Jakarta Barat. Jurnal kesehatan masyarakat, 4(2), 63-71.

BPS. (2018). Statistik tanaman buahbuahan dan sayuran tahunan indonesia 2018.pdf. Jakarta: badan pusat statistik indonesia.

BPS. (2020). Impor buah-buahan menurut negara asal utama 2016$2019 . \quad$ Retrieved from https://www.bps.go.id/statictable/ 2019/02/14/2010/impor-buahbuahan-menurut-negara-asalutama-2010-2019.html

BPS Langsa. (2020). Kota langsa dalam angka.

Hasanawi, h., \& kesumawati, n. (2015). Studi Persepsi Konsumen Terhadap Pemasaran Sale Pisang Dalam Kemasan. Jurnal agroqua, 13(2), 3445.

Mahmudah, n. (2019). Analisis FaktorFaktor Yang Mempengaruhi Minat Mahasiswa STEI SEBI Jurusan Akuntansi Syariah Terhadap Profesi Akuntan Publik. Jurnal akuntansi dan keuangan islam, 2(1), 83-100. Https://doi.org/10.35836/jakis.v2i 1.54

Permadi, r., \& winarti, l. (2015). Analisis Sikap Konsumen Terhadap Atribut Buah Pisang Kepok (Studi Kasus Konsumen Di Tiga Kota Kuala Pembuang, Sampit, Dan Palangkaraya). Media sains, 8(2), 218-223.

Pradana, a. K., slamet, a. S., \& andrianto, 
m. S. (2018). Analisis Faktor Yang Memengaruhi Pengambilan Keputusan Pembelian Pepaya Calina, $9(2)$. Https://doi.org/10.32832/jmuika.v9i2.1562

Rachman, b. N., mustika, i. G., \& kusumawati, i. G. A. W. (2017). Faktor Yang Berhubungan Dengan Perilaku Konsumsi Buah Dan Sayur Siswa Smp Di Denpasar. Jurnal gizi indonesia, 6(1).

Rahayu, j. N., fauziyah, e., \& ariyani, a. H. (2012). Preferensi Konsumen Terhadap Buah Apel Impor Di Toko Buah Hokky Dan Pasar Tradisional Ampel Surabaya. Jurnal agriekonomika, 1(april), 52-67.

Rizkyana, o., nugroho, f. A., \& anggraeny, o. (2017). Asupan Sayur Dan Buah Dengan Variasi Warnanya Pada Siswa Sd Insan Permata Malang. Indonesian journal of human nutrition, 4(1), 12-22.

Rochaeni, s. (2013). Analisis Persepsi,
Kesadaran, Dan Preferensi Konsumen Terhadap Buah Lokal. Jurnal agribisnis, 7(1).

Simbolon, n. S., zargustin, d., \& nizar, r. (2018). Hubungan Persepsi Konsumen Dengan Perilaku Mengkonsumsi Buah Lokal Di Pasar Tradisional Arengka Kecamatan Tampan Kota Pekanbaru. Jurnal agribisnis, 20(1), 75-85.

Sumarwan, u., \& palupi, e. (2017). Preferensi Konsumen Terhadap Buah-Buahan Lokal Dan Organik Serta Implikasinya Terhadap Pendidikan Konsumen Cinta Produk Nasional. Jurnal Ilmu Keluarga Dan Konsumen, 10(2), 157-168.

Sungkawa, I., Dwi, P., \& Eva, F. (2015). . Hubungan Antara Persepsi dan Preferensi Konsumen Dengan Pengambilan Keputusan Pembelian Buah Lokal (Studi kasus di Pasar Harjamukti, Pasar Pagi, dan Pasar Kanoman Kota Cirebon). Jurnal Agrijati, 28(1), 79-99. 